\title{
Endovascular Management of Distal ACA Aneurysms: Single- Institution Clinical Experience in 22 Consecutive Patients and Literature Review
}

\author{
D.D. Cavalcanti, A.A. Abla, N.L. Martirosyan, C.G. McDougall, R.F. Spetzler, and F.C. Albuquerque
}

\begin{abstract}
BACKGROUND AND PURPOSE: Distal ACA aneurysms remain difficult to treat with endovascular therapy, but improved technology and experience allows for the treatment of some of these aneurysms with excellent results. The purpose of this study was to assess the status of endovascular treatment of distal ACA aneurysms by comparing our results with recent endovascular and microsurgical series of distal ACA aneurysms.
\end{abstract}

MATERIALS AND METHODS: Between 2000 and 2008, a total of 22 consecutive patients (14 women; mean age, 58.4 years) with distal ACA aneurysms underwent coil placement at Barrow Neurological Institute. Clinical presentations, radiographic findings, endovascular management, and outcomes were reviewed retrospectively.

RESULTS: Of the 22 patients, 13 (59\%) presented with subarachnoid hemorrhage. Six patients were HH grade I or II, 1 was grade III, 5 were grade IV, and 1 was grade V. Frontal lobe hematomas occurred in 5 patients with ruptured aneurysms. The mean aneurysm size was $7.5 \mathrm{~mm}$ (range, 2.8-25 mm); 55\% were smaller than $7 \mathrm{~mm}$. Twelve aneurysms (55\%) arose from the origin of the callosomarginal artery (55\%). Complete occlusion was achieved in $50 \%$ of the cases and near-complete occlusion in $45 \%$. The few periprocedural complications included 1 retroperitoneal hematoma and 1 intraoperative rupture. Four patients had thromboembolic events adequately treated intraprocedurally with abciximab. No deaths occurred in the patients treated.

CONCLUSIONS: The characteristics of the patients and aneurysms treated in our series were comparable to previous reports of endovascular treatment of ACA aneurysms with respect to rupture status. Periprocedural morbidity and mortality rates in our series fared well compared with previous reports, as did our combined rate of complete or near-complete occlusions. Recent advances in endovascular devices and techniques have improved outcomes of distal ACA aneurysms.

ABBREVIATIONS: $\mathrm{ACA}=$ anterior cerebral artery; GOS = Glasgow Outcome Scale; $\mathrm{HH}=$ Hunt and Hess; ICH = intracerebral hematoma; ISAT = International Subarachnoid Aneurysm Trial

A cross various series, distal ACA aneurysms have represented 2 to $9.2 \%$ of all intracranial aneurysms ${ }^{1-6}$ and comprised only $4.4 \%$ of the aneurysms in the ISAT. ${ }^{7}$ Bridging veins, attenuated arachnoid adhesions between the cingulate gyri, deep and narrow exposure of the interhemispheric fissure, adherence of the aneurysm dome to the parenchyma, high perioperative rupture rates, and difficulty in controlling the parent vessel have all been considered obstacles to the microsurgical management of these relatively uncommon lesions. ${ }^{8-11}$ Concomitantly, controlling the microcatheter in its distal vascular distribution and the small size of distal ACA

Received June 13, 2012; accepted after revision September 22.

From the Division of Neurological Surgery, Barrow Neurological Institute, St. Joseph's Hospital and Medical Center, Phoenix, Arizona.

Please send correspondence to Felipe C. Albuquerque, MD, c/o Neuroscience Publications, Barrow Neurological Institute, 350 W. Thomas Rd, Phoenix, AZ 85013 ;

E-mail: neuropub@dignityhealth.org

http://dx.doi.org/10.3174/ajnr.A3408 aneurysms are difficulties associated with their endovascular treatment. $^{12,13}$

We report our 8-year experience managing these lesions and compare our outcomes, focusing on periprocedural results, with those of recent endovascular series and with surgical series of patients with distal ACA aneurysms.

\section{MATERIALS AND METHODS}

The medical records of patients with distal ACA aneurysms treated with endovascular techniques at the Barrow Neurological Institute were reviewed retrospectively for rupture status, clinical presentation, radiographic features, endovascular management, time to treatment, occlusion and recurrence rates, complications, and outcome at last follow-up. A 100\% occlusion of the aneurysmal sac was considered complete. Near-complete occlusion was used for aneurysms judged to be $90 \%$ or more occluded as previously reported. ${ }^{14}$

We assessed functional outcome by using the GOS. A GOS $\geq 4$ was considered favorable. 
Table 1: Demographics, outcomes, and mortality rates from 7 endovascular series of distal ACA aneurysms

\begin{tabular}{|c|c|c|c|c|c|c|c|c|c|c|c|c|c|}
\hline \multirow[b]{2}{*}{ Reference } & \multirow{2}{*}{$\begin{array}{l}\text { No. } \\
\text { Pts. F }\end{array}$} & \multirow{2}{*}{$\begin{array}{c}\text { No. } \\
\text { Ruptured }\end{array}$} & \multirow{2}{*}{\multicolumn{4}{|c|}{ 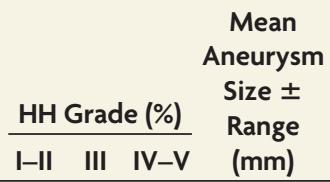 }} & \multirow{2}{*}{$\begin{array}{c}\text { Immediate } \\
\text { Occlusion: } \\
\text { no. (\%) }\end{array}$} & \multirow{2}{*}{$\begin{array}{l}\text { Immediate } \\
\text { Near- } \\
\text { Occlusion } \\
\text { or Better } \\
(90 \%-100 \%)\end{array}$} & \multirow{2}{*}{$\begin{array}{c}\text { Overall } \\
\text { Favorable } \\
\text { Outcome } \\
(\%)\end{array}$} & \multirow{2}{*}{$\begin{array}{c}\text { Favorable } \\
\text { Outcome } \\
\text { Unruptured } \\
(\%)\end{array}$} & \multirow{2}{*}{$\begin{array}{c}\text { Favorable } \\
\text { Outcome } \\
\text { HH I-II } \\
(\%)\end{array}$} & \multirow{2}{*}{$\begin{array}{c}\text { Favorable } \\
\text { Outcome } \\
\text { HH III-V } \\
\text { (\%) }\end{array}$} & \multirow{2}{*}{$\begin{array}{c}\text { Mortality: } \\
\text { Ruptured } \\
\text { Aneurysms } \\
\text { (\%) }\end{array}$} \\
\hline & & & & & & & & & & & & & \\
\hline $\begin{array}{l}\text { Menovsky et al, } \\
2002^{10}\end{array}$ & 12 & 12 & 58.3 & 25 & 16.7 & $5.7 \pm 2.8$ & $11(91.7)$ & $12(100)$ & 100 & - & 100 & 100 & 0 \\
\hline $\begin{array}{l}\text { Keston et al, } \\
2004^{13}\end{array}$ & 18 & 17 & 88.2 & 5.9 & 5.9 & - & $9(52.9)$ & $14(82.3)$ & 100 & 100 & 100 & 100 & 0 \\
\hline $\begin{array}{l}\text { Nguyen et al, } \\
2007^{17}\end{array}$ & 25 & 12 & - & - & - & 7.5 & $20(74)$ & $\mathrm{N} / \mathrm{A}$ & 88 & - & - & - & 16.7 \\
\hline $\begin{array}{l}\text { Pandey et al, } \\
2007^{16}\end{array}$ & 28 & 27 & 48.2 & 22.2 & 29.6 & 5.5 & $25(89.3)$ & $26(92.9)$ & 67.9 & 100 & 84.6 & 50 & 3.7 \\
\hline $\begin{array}{l}\text { Waldenberger } \\
\text { et al, } 2008^{15}\end{array}$ & 29 & 21 & 33.3 & 33.3 & 33.3 & $5.4 \pm 3$ & $27(93)$ & $27(93)$ & 59 & 85.7 & 85.7 & 12.5 & 28.6 \\
\hline $\begin{array}{c}\text { Vora et al, } \\
2010^{18}\end{array}$ & 26 & 13 & 46.2 & 38.5 & 15.4 & $5.7 \pm 2.8$ & 15 (57.7) & $22(84.6)$ & 64.2 & 92.3 & 66.7 & 33.3 & 15.4 \\
\hline Current series & 22 & 13 & 46.2 & 7.7 & 46.2 & $7.5 \pm 5.6$ & $11(50)$ & $21(95.5)$ & 77.3 & 88.9 & 83.3 & 57.1 & 0 \\
\hline
\end{tabular}

Note:-Favorable outcome is a Glasgow Outcome Scale score of 4 or 5.

Table 2: Demographics, outcomes, and mortality rates from microsurgical clipping series of distal ACA aneurysms

\begin{tabular}{|c|c|c|c|c|c|c|c|c|c|c|c|}
\hline \multirow[b]{2}{*}{ Reference } & \multirow[b]{2}{*}{$\begin{array}{l}\text { No. } \\
\text { Pts. }\end{array}$} & \multirow[b]{2}{*}{$\begin{array}{c}\text { No. } \\
\text { Ruptured }\end{array}$} & \multicolumn{3}{|c|}{ HH Grade (\%) } & \multirow{2}{*}{$\begin{array}{c}\text { Mean } \\
\text { Aneurysm } \\
\text { Size }(\mathrm{mm})\end{array}$} & \multicolumn{4}{|c|}{ Favorable Outcome (GOS 4 or 5 ) } & \multirow{2}{*}{$\begin{array}{c}\text { Mortality: } \\
\text { Ruptured } \\
\text { Aneurysms } \\
\text { (\%) }\end{array}$} \\
\hline & & & I-II & III & IV-V & & $\begin{array}{c}\text { Overall } \\
(\%)\end{array}$ & $\begin{array}{c}\text { Unruptured } \\
(\%)\end{array}$ & $\begin{array}{c}\text { HH I-II } \\
(\%)\end{array}$ & $\begin{array}{c}\text { HH III-V } \\
(\%)\end{array}$ & \\
\hline Proust et al, $1997^{2}$ & 43 & 35 & 42.9 & 25.7 & 31.4 & - & 69.8 & 87.5 & 80 & 55 & 14.3 \\
\hline de Sousa et al, $1999^{1}$ & 72 & 65 & 69.2 & 1.5 & 29.2 & - & 84.7 & 100 & 88.9 & 70 & 7.7 \\
\hline Steven et al, $2007^{8}$ & 59 & 36 & 36.1 & 36.1 & 27.7 & 7.9 & 71.2 & 91.3 & 92.3 & 39.1 & 16.7 \\
\hline Lehecka et al, $2007^{25}$ & 62 & 258 & 48.9 & 18.5 & 32.6 & $4.8^{*}$ & 78.2 & 86.5 & 90.2 & 58.6 & 13 \\
\hline
\end{tabular}

* Value corresponds to all 470 patients in that study, including conservatively managed cases.

\section{Analysis of Endovascular and Microsurgical Series of Distal ACA Aneurysms}

We searched PubMed for endovascular and microsurgical series on both ruptured and unruptured distal ACA aneurysms containing well-reported patient data and detailed outcome assessments on the basis of either the GOS or the modified Rankin Scale. Surgical series that included lesions not managed with the operating microscope were excluded. We analyzed 6 series on the endovascular management of distal ACA aneurysms published since 2004 that had consistent and homogeneous results. ${ }^{10,13,15-18}$ When our series was added to these 6 reports, our assessment of the current status of endovascular coiling was based on 160 patients with distal ACA aneurysms (Table 1).

The functional status of patients in 4 large series of microsurgical management of distal ACA aneurysms ${ }^{1,2,8,19}$ was compared with those in the endovascular series (Table 2).

\section{RESULTS}

Between November 2000 and December 2008, a total of 22 patients ( 14 women, 8 men; mean age, $58.4 \pm 13.3$ years; age range, 32-87 years) with distal ACA aneurysms underwent endovascular coiling (Table 3). Thirteen patients $(59.1 \%)$ presented with subarachnoid hemorrhage attributable to aneurysms of the distal ACA. The mean age of patients with ruptured aneurysms was $56.3 \pm 14.0$ years and that of patients with unruptured aneurysms was $61.3 \pm 12.2$ years (Table 4 ). The features of all aneurysms and associated aneurysms are shown in Table 5. Results from previous endovascular and surgical series of distal ACA aneurysms are tabulated in Tables 1 and 2, respectively.

\section{Ruptured Aneurysms}

All 13 ruptured distal ACA aneurysms (Figs 1 and 2) were coiled within the first 4 days of hospitalization at our institution; $84.6 \%$ were coiled within the first 48 hours. At the end of the procedure, complete occlusion was observed in 7 patients and near-complete occlusion in 6 patients (Table 3 ). The mean length of hospitalization was 16.2 days (range, 4-34 days). Follow-up was limited and was considered a weakness of the study; of the 8 patients with additional follow-up after discharge, 7 (87.5\%) had a favorable outcome at their last clinical consultation. Patients were observed for a mean of 12.5 months (range, 0-50 months).

Again, as for clinical follow-up, radiographic follow-up was limited, with angiography available for 7 patients, all of whom had a complete occlusion. Only 1 patient experienced a recurrence, which was discovered 4 months after treatment. The lesion was recoiled. A third intervention was necessary to address a second recurrence 3 years later. Follow-up angiography showed complete occlusion 1 year after that treatment. There were no cases of rebleeding in the limited follow-up period.

\section{Unruptured Aneurysms}

In 9 patients treated for unruptured aneurysms, complete occlusion was achieved in 4 patients $(44.4 \%)$ and near-complete occlusion in 4 (Table 4). The patients were hospitalized for a mean of 4.6 days (range, 1-26 days) and were observed for a mean of 18.4 months (range, 1.5-62 months). At discharge, 7 patients (77.8\%) had a GOS score of 5 . Of the 9 patients, 8 had a GOS score of 5 at their last follow-up consultation, which again was of limited duration. 
Table 3: Summary of clinical and radiologic data of 13 patients with ruptured distal ACA aneurysms undergoing coiling

\begin{tabular}{|c|c|c|c|c|c|c|c|c|c|c|}
\hline Patient & Age/Sex & $\begin{array}{l}\mathrm{HH} \\
\text { Grade }\end{array}$ & $\begin{array}{l}\text { Fisher } \\
\text { Grade }\end{array}$ & $\mathrm{ICH}$ & $\begin{array}{l}\text { Associated } \\
\text { Aneurysms } \\
\text { Elsewhere }\end{array}$ & $\begin{array}{c}\text { Initial } \\
\text { Occlusion } \\
(\%)\end{array}$ & $\begin{array}{c}\text { Initial } \\
\text { GOS }\end{array}$ & $\begin{array}{l}\text { Final } \\
\text { GOS }\end{array}$ & $\begin{array}{l}\text { Follow-Up } \\
\text { (months) }\end{array}$ & Complications \\
\hline
\end{tabular}

\begin{tabular}{|c|c|c|c|c|c|c|c|c|c|c|}
\hline $1^{a}$ & $53 / F$ & IV & IV & Yes & - & 100 & 3 & 5 & 50 & - \\
\hline 2 & $74 / F$ & II & III & No & - & $>95$ & 4 & - & 0 & - \\
\hline 3 & $39 / F$ & I & III & No & 1 & $>95$ & 5 & 5 & 48 & Retroperitoneal hematoma $^{b}$ \\
\hline 4 & $40 / F$ & IV & IV & Yes & - & 95 & 2 & - & 0 & - \\
\hline 5 & $59 / F$ & I & III & No & 2 & 100 & 5 & - & 0 & - \\
\hline 6 & $32 / \mathrm{M}$ & II & III & No & - & 100 & 5 & 5 & 5 & - \\
\hline 7 & 51/M & II & IV & Yes & 7 & 100 & 3 & 3 & 25 & - \\
\hline 8 & $63 / F$ & III & IV & No & 1 & 95 & 5 & 5 & 6 & - \\
\hline 9 & $76 / M$ & IV & IV & Yes & 1 & 100 & 2 & - & 0 & - \\
\hline 10 & $72 / \mathrm{F}$ & IV & IV & Yes & 4 & 100 & 4 & 4 & 3 & - \\
\hline 11 & $51 / \mathrm{M}$ & V & IV & No & - & 90 & 2 & - & 0 & Thrombus formation $^{c}$ \\
\hline 12 & $54 / F$ & IV & IV & No & - & 100 & 4 & 5 & 11 & Thrombus formation ${ }^{c}$ \\
\hline 13 & $68 / F$ & I & III & No & 2 & $>95$ & 5 & 5 & 1.5 & - \\
\hline
\end{tabular}

F indicates female; $\mathrm{M}$, male; $\mathrm{ICH}$, intracerebral hematoma.

a Patient had 2 recurrences, one after 4 months and a second after 3 years. Both were recoiled. One-year follow-up angiogram confirmed complete occlusion.

${ }^{\mathrm{b}}$ Conservative management.

${ }^{c}$ Abciximab infusion reversed thrombus formation.

Table 4: Summary of clinical and radiologic data of 9 patients with unruptured distal ACA aneurysms undergoing coiling

\begin{tabular}{|c|c|c|c|c|c|c|c|c|}
\hline Patient & Age/Sex & Cause of Investigation & $\begin{array}{l}\text { Associated } \\
\text { Aneurysms } \\
\text { Elsewhere }\end{array}$ & $\begin{array}{c}\text { Initial } \\
\text { Occlusion } \\
(\%)\end{array}$ & $\begin{array}{l}\text { Initial } \\
\text { GOS }\end{array}$ & $\begin{array}{l}\text { Final } \\
\text { GOS }\end{array}$ & $\begin{array}{c}F / U \\
\text { (months) }\end{array}$ & Complications \\
\hline $14^{a}$ & $69 / \mathrm{M}$ & TIA + seizures & - & 100 & 3 & 5 & 62 & Thrombus formation $^{\mathrm{b}}$ \\
\hline 15 & $63 / \mathrm{M}$ & Polycystic kidney disease & - & $>95$ & 5 & 5 & 39 & Thrombus formation ${ }^{b}$ \\
\hline 16 & $62 / F$ & Incidental/headache & 3 & 100 & 5 & 5 & 12 & - \\
\hline 17 & $55 / \mathrm{M}$ & Posttraumatic headache & 2 & $>95$ & 5 & 5 & 14 & - \\
\hline 18 & $50 / \mathrm{F}$ & Lightheadedness, dizziness & - & 100 & 5 & 5 & 16 & - \\
\hline 19 & $62 / F$ & Family history, syncope & 2 & $<90$ & 3 & 3 & 1.5 & Intraprocedural rupture \\
\hline 20 & $44 / F$ & History of SAH/MCA clipping 1.5 y before & 2 & 95 & 5 & 5 & 8 & - \\
\hline 21 & $60 / F$ & Syncope & - & 100 & 5 & 5 & 12 & - \\
\hline 22 & $87 / M$ & TIA & - & $>95$ & 5 & 5 & 1.5 & - \\
\hline
\end{tabular}

F/U indicates follow-up; MCA, middle cerebral artery; SAH, subarachnoid hemorrhage; TIA, transient ischemic attack.

${ }^{\text {a }}$ Patient had recurrence on MR angiography 5 months after coiling. Aneurysm was recoiled, and complete occlusion was observed during entire follow-up.

${ }^{\mathrm{b}}$ Abciximab infusion shrunk and stabilized the thrombotic formations.

Table 5: Summary of characteristics of 22 distal ACA aneurysms

\begin{tabular}{lcc}
\multicolumn{1}{c}{ Characteristic } & Ruptured & Unruptured \\
\hline Size $(\mathrm{mm})$ & & \\
Mean \pm SD (range) & $6.2 \pm 3.2(2.8-12)$ & $9.2 \pm 7.8(3-25)$ \\
$<7$ & 7 & 5 \\
$7-14$ & 6 & 2 \\
$14-25$ & - & 1 \\
$>25$ & - & 1 \\
Location & 3 & 2 \\
A2 & 10 & 6 \\
A3 & - & 1 \\
A4/5 & & - \\
Origin at a branching point & 2 & 5 \\
Anterior internal frontal artery & 7 & \\
Callosomarginal artery & & \\
\hline
\end{tabular}

\section{Predictors of Outcome}

As would be expected, a high $\mathrm{HH}$ score at hospital admission was associated with a significantly poor clinical outcome $(P=.006, r=-0.562)$. No correlation was found between overall outcome and other predictive variables, including age, aneurysm size, intracerebral hemorrhage, and associated aneurysms, though the overall outcome at last follow-up was of limited duration. Periprocedural outcomes were excellent and included only 1 retroperitoneal hematoma and 1 intraoperative rupture. Four patients required abciximab infusion for thrombus formation,

Angiographic follow up was limited and was available for 6 of the 9 patients. Five patients had completely occluded lesions; a sixth patient maintained a near-total occlusion. In 1 patient, aneurysm regrowth was observed on follow-up MR angiography 5 months after embolization (Fig 3). The lesion was again coiled, and complete occlusion was observed during a 5-year follow-up period. which developed during the procedure.

\section{DISCUSSION}

\section{Evolution of Endovascular Management of Distal ACA Aneurysms}

In the 1990s, favorable results from centers experienced with microsurgical clipping, combined with the low incidence of distal 

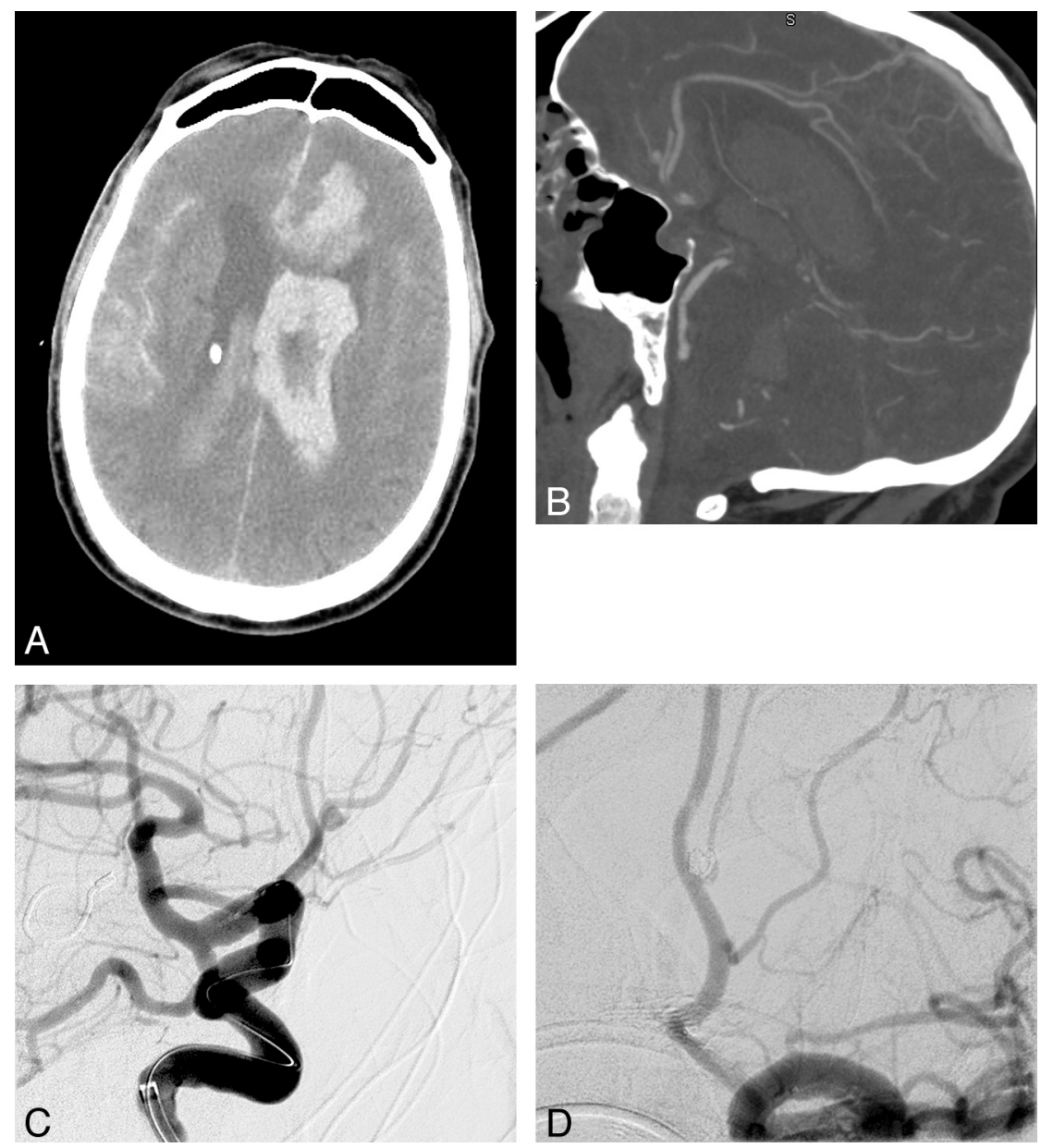

FIG 1. A, Initial CT scan of Patient 9 (Fisher grade IV). B, CT angiogram showed a 2.8-mm aneurysm. The patient underwent coil embolization. Preprocedural $(C)$ and postprocedural $(D)$ angiograms. Three coils were delivered. Complete occlusion was achieved. Used with permission from Barrow Neurological Institute.
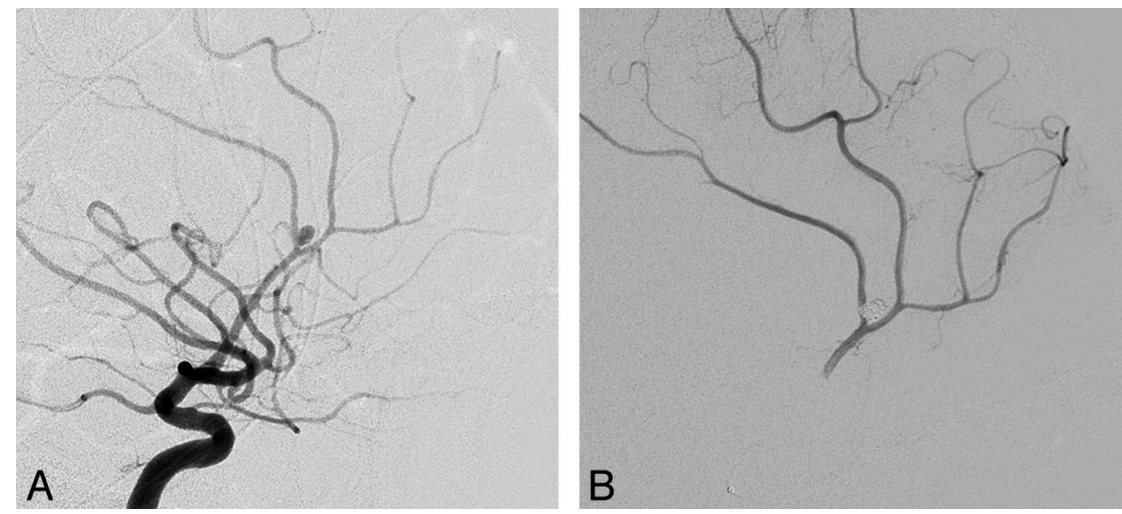

FIG 2. A, Angiogram of a ruptured distal ACA aneurysm in Patient 12 reveals a 3-mm aneurysm arising from the $A 3$ segment. $B$, Lateral view of a selective injection of the right pericallosal artery after coiling. The aneurysm was packed with 2 coils. Total occlusion was achieved. Used with permission from Barrow Neurological Institute.

ACA aneurysms, discouraged early referrals for endovascular care. Moreover, the peripheral location of distal ACA aneurysms and their small size precluded successful treatment by endovascular means with the use of developing technology. ${ }^{12,15}$ Pierot et $\mathrm{al}^{12}$ pioneered the endovascular management of 8 cases of distal ACA aneurysms in 1996, but embolization was successful in only $25 \%$. Although based on a small series, Menovsky et $\mathrm{al}^{10}$ first proposed coiling distal ACA aneurysms as an alternative to clipping. Initial complete occlusion was obtained in $91.7 \%$ of their 12 cases. At last follow-up, $66.7 \%$ of the aneurysms remained completely occluded, no patient had again presented with bleeding, and $91.7 \%$ of the patients achieved a GOS score of 5 (Table 1). In a large microsurgical series primarily composed of patients with a good clinical grade, $83 \%$ of the patients with a ruptured distal ACA 

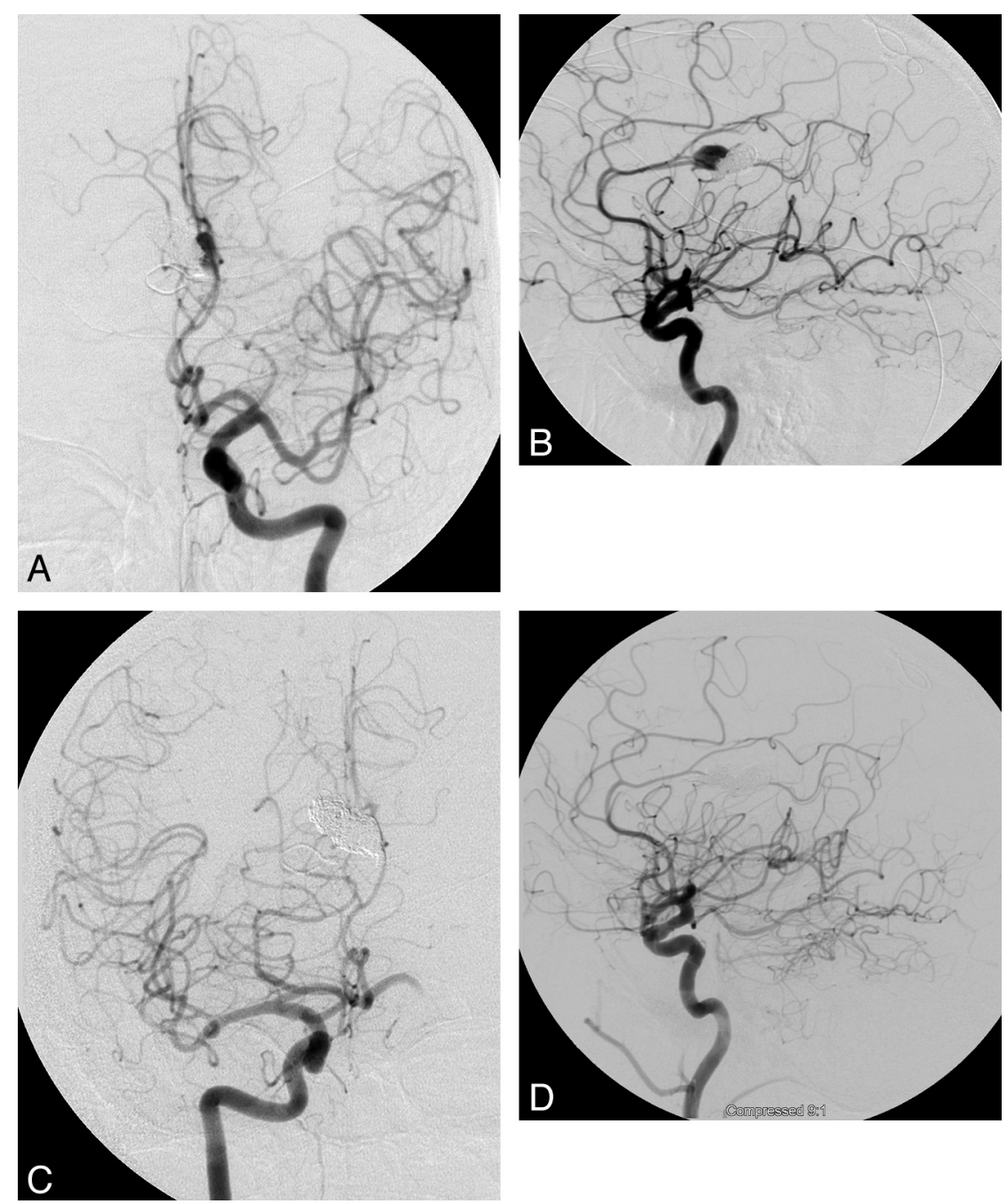

FIG 3. Recurrence was observed in 2 of 13 patients who underwent follow-up angiography in our institution. Anteroposterior $(A)$ and lateral $(B)$ angiography at 5 months of a 69-year-old woman diagnosed with a 20-mm unruptured distal ACA aneurysm who underwent uneventful coiling. The aneurysm regrew after coil compaction to almost the initial size. Anteroposterior $(C)$ and lateral $(D)$ projections immediately after retreatment. Total occlusion was obtained. Used with permission from Barrow Neurological Institute.

aneurysm had a favorable GOS score, and the mortality rate was 7.7\% (Table 2). ${ }^{1}$ Although our follow-up was limited, periprocedural occlusion rates in our series compare well against historical controls. Of 22 patients, 11 (50\%) experienced complete occlusion and another $10(45 \%)$ had near-complete occlusion. Furthermore, there were no periprocedural deaths and only 1 instance each of intraprocedural rupture and retroperitoneal hematoma formation. Thromboembolic events were treated successfully with abciximab infusion in 4 patients.

Nguyen et $\mathrm{al}^{17}$ pointed out the caveat that the rate of intraprocedural rupture was higher when these lesions were coiled, compared with coiled aneurysms located elsewhere. They reported 3 perforations in 25 patients undergoing endovascular management of distal ACA aneurysms and suggested that the small size and distal distribution of the aneurysms could explain the high rate of rupture. ${ }^{17}$ Overall, in 7 endovascular series that enrolled 160 patients, including the current series, intraoperative rupture occurred in only $5.6 \% .^{10,13,15-18}$

\section{Recurrences}

Nguyen et $\mathrm{al}^{17}$ emphasized the recurrence rate of coiled distal ACA aneurysms, though the rate was not significantly higher than that for intracranial aneurysms coiled elsewhere. The cumulative rate of distal ACA aneurysm recurrence was 52.6\%. A major recurrence, an event leading to retreatment, was observed in $21 \%$. Pandey et $\mathrm{al}^{16}$ reported an $18 \%$ recurrence rate at a mean follow-up of 16.5 months. In a similar circumstance, Waldenberger et $\mathrm{al}^{15}$ identified a recurrence in $17.2 \%$ of patients at 6 -month follow-up examination. Although it is difficult to draw strong conclusions on the basis of the length of follow up, we observed aneurysm regrowth in 2 patients (15.4\%) at a mean follow-up of 15 months. Both of our patients underwent coiling again, and the aneurysms remained completely obliterated.

At a mean follow-up of 12.3 months, Raymond et $\mathrm{al}^{20}$ found recurrences in $33.6 \%$ of 381 intracranial aneurysms at various sites after endovascular treatment. They stressed that a main factor involved in recurrence, besides the initial occlusion rate and 
rupture, is the large size of an aneurysm (an infrequent feature of distal ACA aneurysms).$^{20}$ Furthermore, the ISAT showed that the clinical implications of recurrences are unknown. ${ }^{7,21,22}$ For comparison, Tsutsumi et $\mathrm{al}^{23}$ found regrowth in $2.3 \%$ of 220 patients undergoing initial complete surgical obliteration of an intracranial aneurysm at a mean follow-up of 10 years. A review of 147 consecutive surgically treated aneurysms at our institution revealed a recurrence in $1.5 \%$ of completely obliterated aneurysms, but a regrowth occurred in $41.7 \%$ of those in which a neck remnant was observed on initial postoperative angiography. ${ }^{24}$ A neck remnant may lead to aneurysm regrowth, but its presence may not necessarily be indicative or predictive of an aneurysm that is unsecured or is more likely to rupture than a completely occluded aneurysm. The risk for subarachnoid hemorrhage from a neck remnant remains unclear.

\section{Immediate Occlusion Rates in Microsurgical Series and Subsequent Rebleeds}

In 1999, de Sousa et $\mathrm{al}^{1}$ observed an impressive $100 \%$ rate of complete occlusion on routine postoperative angiography after treating 74 distal ACA aneurysms with surgery, though their longterm follow-up was limited. Lehecka et $\mathrm{al}^{19}$ reported a satisfactory occlusion rate of $95 \%$ of 362 patients undergoing microsurgical treatment. In microsurgical clipping, recurrent subarachnoid hemorrhage can affect $2.7 \%$ of patients with complete occlusion of an intracranial aneurysm. ${ }^{23}$ An identical rebleed rate was found in 43 patients in a surgical series focusing specifically on distal ACA aneurysms. ${ }^{2}$ In a large series of 262 clipped distal ACA aneurysms, the rebleeding rate was only $0.4 \% .^{25}$ Although immediate complete occlusion with clipping occurs at an incredibly high rate, the rate of immediate occlusion with coiling, whether complete or near-complete, was more than $95 \%$ in this series and compared favorably with previous reports (Table 2).

\section{Clinical Outcomes in Endovascular and Microsurgical Series, Focusing on Distal ACA Aneurysms}

In 1999, Vanninen et $\mathrm{al}^{26}$ reported the first randomized prospective study comparing endovascular treatment of ruptured intracranial aneurysms with surgical clipping. A late analysis at 12 months showed no significant difference in the clinical outcomes of both groups managing ACA aneurysms, but the procedurerelated mortality rate was higher among patients undergoing surgical clipping.

The endovascular group in the ISAT had better outcomes, even after 7 years of follow-up. ${ }^{27}$ However, this finding could not be generalized to a specific type of aneurysm such as distal ACA aneurysms. $^{16,28}$

Studies have shown that the admission $\mathrm{HH}$ grade is a significant predictor of poor clinical outcome..$^{8,15,16,19,29}$ Intracerebral hemorrhage on initial CT also predicted a poor outcome in patients undergoing either endovascular or microsurgical treatment of distal ACA aneurysms. ${ }^{8,15,19}$ The large number of distal ACA aneurysms surgically managed by Lehecka et $\mathrm{al}^{19}$ yielded a longer list of predictors. Intraventricular hemorrhage, severe preoperative hydrocephalus, age, and rebleeding before treatment were associated with unfavorable clinical outcomes in their series.

\section{Periprocedural Morbidity and Mortality Rates}

Endovascular management of ACA aneurysms was associated with a mean morbidity rate of $8.8 \%$ and ranged from $0 \%-$ $17.2 \% .{ }^{10,13,15-18}$ In 2 surgical series providing satisfactory data, the mean rate of morbidity among 405 patients was $14.3 \%$. $^{2,19}$ Finally, the mean mortality rate in patients with distal ACA aneurysms undergoing endovascular treatment was $8.8 \%$ in the assessed series, including ours, and ranged from $0 \%-$ $20.7 \% .{ }^{10,13,15-18}$ On analysis of only the cases of patients with ruptured aneurysms $(n=124)$, the mortality rate for endovascular treatment reached $11.3 \%$. Overall, in 7 endovascular series that enrolled 160 patients, including the current series, intraoperative rupture occurred in only $5.6 \% .^{10,13,15-18}$

\section{CONCLUSIONS}

In our series, the periprocedural morbidity and mortality rates were similar to the risk profile of other reported series and demonstrate that these aneurysms can be treated safely by endovascular means. Recent advances in endovascular devices and techniques have improved treatment outcomes of distal ACA aneurysms, as seen in our series, with a favorable safety profile on the basis of analysis of periprocedural treatment success and complication rates.

Disclosures: Daniel Cavalcanti—UNRELATED: Employment: Paulo Niemeyer State Brain Hospital. Cameron McDougall—UNRELATED: Consultancy: Covidien, Gore.

\section{REFERENCES}

1. de Sousa AA, Dantas FL, de Cardoso GT, et al. Distal anterior cerebral artery aneurysms. Surg Neurol 1999;52:128-35; discussion 135-36

2. Proust F, Toussaint $\mathrm{P}$, Hannequin $\mathrm{D}$, et al. Outcome in $\mathbf{4 3}$ patients with distal anterior cerebral artery aneurysms. Stroke 1997;28: 2405-09

3. Ohno K, Monma S, Suzuki R, et al. Saccular aneurysms of the distal anterior cerebral artery. Neurosurgery 1990;27:907-12; discussion 912-13

4. Mann KS, Yue CP, Wong G. Aneurysms of the pericallosal-callosomarginal junction. Surg Neurol 1984;21:261-66

5. Yaşargil MG, Carter LP. Saccular aneurysms of the distal anterior cerebral artery. J Neurosurg 1974;40:218-23

6. McKissock W, Paine KW, Walsh LS. An analysis of the results of treatment of ruptured intracranial aneurysms, report of 772 consecutive cases. J Neurosurg 1960;17:762-76

7. Molyneux A, Kerr R, Stratton I, et al. International Subarachnoid Aneurysm Trial (ISAT) of neurosurgical clipping versus endovascular coiling in 2143 patients with ruptured intracranial aneurysms: a randomised trial. Lancet 2002;360:1267-74

8. Steven DA, Lownie SP, Ferguson GG. Aneurysms of the distal anterior cerebral artery: results in $\mathbf{5 9}$ consecutively managed patients. Neurosurgery 2007;60:227-33; discussion 234

9. Kawashima M, Matsushima T, Sasaki T. Surgical strategy for distal anterior cerebral artery aneurysms: microsurgical anatomy. $J \mathrm{Neu}$ rosurg 2003;99:517-25

10. Menovsky T, van Rooij WJ, Sluzewski M, et al. Coiling of ruptured pericallosal artery aneurysms. Neurosurgery 2002;50:11-14; discussion $14-15$

11. Snyckers FD, Drake CG. Aneurysms of the distal anterior cerebral artery. A report on 24 verified cases. S Afr Med J 1973;47:1787-91

12. Pierot L, Boulin A, Castaings L, et al. Endovascular treatment of pericallosal artery aneurysms. Neurol Res 1996;18:49-53

13. Keston P, White PM, Horribine L, et al. The endovascular manage- 
ment of pericallosal artery aneurysms. J Neuroradiol 2004;31: 384-90

14. Ferns SP, Sprengers ME, van Rooij WJ, et al. Coiling of intracranial aneurysms: a systematic review on initial occlusion and reopening and retreatment rates. Stroke 2009;40:e523-29

15. Waldenberger P, Petersen J, Chemelli A, et al. Endovascular therapy of distal anterior cerebral artery aneurysms-an effective treatment option. Surg Neurol 2008;70:368-77

16. Pandey A, Rosenwasser RH, Veznedaroglu E. Management of distal anterior cerebral artery aneurysms: a single institution retrospective analysis (1997-2005). Neurosurgery 2007;61:909-16; discussion 916-17

17. Nguyen TN, Raymond J, Roy D, et al. Endovascular treatment of pericallosal aneurysms. J Neurosurg 2007;107:973-76

18. Vora N, Thomas AJ, Gupta R, et al. Endovascular treatment of distal anterior cerebral artery aneurysms: technical results and review of the literature. J Neuroimaging 2010;20:70-73

19. Lehecka $M$, Lehto $H$, Niemelä $M$, et al. Distal anterior cerebral artery aneurysms: treatment and outcome analysis of 501 patients. Neurosurgery 2008;62:590-601; discussion 590-601

20. Raymond J, Guilbert F, Weill A, et al. Long-term angiographic recurrences after selective endovascular treatment of aneurysms with detachable coils. Stroke 2003;34:1398-403

21. Byrne JV, Sohn MJ, Molyneux AJ, et al. Five-year experience in using coil embolization for ruptured intracranial aneurysms: outcomes and incidence of late rebleeding. J Neurosurg 1999;90:656-63

22. Murayama Y, Nien YL, Duckwiler G, et al. Guglielmi detachable coil embolization of cerebral aneurysms: 11 years' experience. J Neurosurg 2003;98:959-66

23. Tsutsumi K, Ueki K, Usui M, et al. Risk of recurrent subarachnoid hemorrhage after complete obliteration of cerebral aneurysms. Stroke 1998;29:2511-13

24. David CA, Vishteh AG, Spetzler RF, et al. Late angiographic follow-up review of surgically treated aneurysms. J Neurosurg 1999;91: 396-401

25. Lehecka M, Niemelä $M$, Seppänen J, et al. No long-term excess mortality in 280 patients with ruptured distal anterior cerebral artery aneurysms. Neurosurgery 2007;60:235-40; discussion 240-41

26. Vanninen R, Koivisto $T$, Saari $T$, et al. Ruptured intracranial aneurysms: acute endovascular treatment with electrolytically detachable coils-a prospective randomized study. Radiology 1999;211: 325-36

27. Molyneux AJ, Kerr RS, Yu LM, et al. International Subarachnoid Aneurysm Trial (ISAT) of neurosurgical clipping versus endovascular coiling in 2143 patients with ruptured intracranial aneurysms: a randomised comparison of effects on survival, dependency, seizures, rebleeding, subgroups, and aneurysm occlusion. Lancet 2005;366:809-17

28. Sade B, Mohr G. Critical appraisal of the International Subarachnoid Aneurysm Trial (ISAT). Neurol India 2004;52:32-35

29. Natarajan SK, Sekhar LN, Ghodke B, et al. Outcomes of ruptured intracranial aneurysms treated by microsurgical clipping and endovascular coiling in a high-volume center. AJNR Am J Neuroradiol 2008;29:753-59 